\title{
Genetic variability and the ecology of geographic range: a test of the central-marginal hypothesis in Australian scincid lizards
}

\author{
Sonal Singhal ${ }^{1}$, John Wrath $^{1}$, and Daniel Rabosky ${ }^{2}$ \\ ${ }^{1} \mathrm{CSU}$ Dominguez Hills \\ ${ }^{2}$ University of Michigan
}

December 3, 2021

\begin{abstract}
For many species, both local abundance and regional occupancy are highest near the center of their geographic distributions. One hypothesis for this pattern is that niche suitability declines with increasing distance from a species geographic center, such that populations near range margins are characterized by reduced density and increased patchiness. In these smaller edge populations, genetic drift is more powerful, leading to the loss of genetic diversity. This simple verbal model has been formalized as the central-marginal hypothesis, which predicts that core populations should have greater genetic diversity than edge populations. However, demographic shifts over time can generate a similar pattern. For example, in species with expanding ranges, populations at the range edge experience serial founder effects, creating a gradient of declining genetic diversity from the range core to edge. Testing the central-marginal hypothesis properly thus requires us to consider the confounding role of historical demography. Here, we account for the role of history in testing the central-marginal hypothesis using a genomic dataset of 25 species-level taxa of Australian skink lizards (genus: Ctenotus and Lerista). We found support for the central-marginal hypothesis in 16 of our 25 taxa, of which eight taxa recovered significant support. Unexpectedly, species with the strongest evidence for range expansion were the least likely to follow predictions of the central-marginal hypothesis. The majority of these species had range expansions that originated at the range edge, which led to lower genetic diversity at the range edge compared to the core, contrary to the central-marginal hypothesis.
\end{abstract}

\section{Hosted file}

center-marginal hypothesis in Australian lizards - Google Docs.pdf available at https: //authorea.com/users/50761/articles/547910-genetic-variability-and-the-ecology-ofgeographic-range-a-test-of-the-central-marginal-hypothesis-in-australian-scincid-lizards 